\title{
Resistance to Ketosis in Moderately Obese Patients: Influence of Fatty Liver
}

\author{
Toshiki Inokuchi, Miyuki Orita, Kenji Imamura, Toshiko Takao and Sho Isogai
}

To elucidate whether the presence of fatty liver influences ketogenesis in obesity, the metabolic and hormonal changes in basal and low-dose epinephrine (EPI)-stimulated states were studied in 12 obese patients (OB) with normal glucose tolerance, consisting of 6 without fatty liver (OBN) and 6 with fatty liver (OBF). In the basal state, the total ketone body (TKB) concentration and the TKB to free fatty acid (FFA) ratio were significantly $(p<0.01)$ lower in the OBF than in the OBN group, despite elevated, but comparable, FFA levels in both groups. The basal FFA level and the TKB/FFA ratio correlated with the degree of fatty liver $(p<0.05-0.01)$. EPI infusion resulted in accelerated lipolysis and diminished FFA-induced ketogenesis, similar to the findings of the basal data. These results suggest that fatty liver per se is related to diminished FFA-induced ketogenesis, leading to resistance to ketosis in obestiy.

(Internal Medicine 31: 978-983, 1992)

Key words: obesity, free fatty acid, total ketone body, epinephrine infusion

\section{Introduction}

It has long been recognized that obese people do not readily develop ketosis during weight-reducing regimens. However, the mechanism by which obese subjects have resistance to ketosis is still controversial (1-4). One reason for the discrepancy in previous observations might be due to the heterogenous conditions of the patients studied. Although ketone bodies are well-known to be mainly synthesized in the liver, ketone body production in obese patients with fatty liver has not yet been well defined. We, therefore, investigated ketone body metabolism in both basal and low-dose epinephrine (EPI) stimulated states in moderately obese patients with normal glucose tolerance, in an attempt to determine whether or not the presence of fatty liver influences ketogenesis in obesity.

\section{Subjects and Methods}

The purpose, nature, and potential risks of the study were explained to all potential subjects, and informed consent was obtained from a total of 17 participants with no family history of diabetes. Twelve obese patients were recruited for this study on the basis of a normal glucose tolerance and a body mass index (BMI; $\mathrm{kg} / \mathrm{m}^{2}$ ) of greater than 30 . The normal weight group consisted of 5 subjects, each having a BMI of less than 25 . All subjects were healthy and had maintained a constant body weight for at least 3 months before the study; none of them was taking medication known to affect glucose or free fatty acid (FFA) metabolism, nor were any drinking alcohol. Also, none of the obese patients had been on a weight-reduction program involving caloric restriction. All consumed their typical diets before the investigation.

All blood tests were conducted under standard conditions in the morning after an overnight fast. A standard oral glucose tolerance test $(75 \mathrm{~g})$ was performed, and the results were interpreted according to WHO (1985) criteria. In order to investigate the effect of much higher FFA concentrations in plasma on ketogenesis in our subjects, EPI infusion rates were chosen so as to approximate the plasma levels found in physiological elevation of EPI (5). The subjects were kept at bedrest for at least 30 minutes before the start of infusion. Intravenous infusion of EPI, dilution in $0.9 \%$ saline containing $0.5 \mathrm{mg} / \mathrm{ml}$ ascorbic acid to present EPI degradation, was given in a stepwise fashion from 25 to $50 \mathrm{ng} / \mathrm{kg}$ of fat-free mass (FFM)/min by microinfusion pump (Nihonkoden TFV-1200A), each dose lasting 30 minutes; FFM was calculated using the equations reported by Leonhardt et al (6). Blood samples were taken from an

From the Second Department of Internal Medicine, Toho University School of Medicine, Tokyo

Received for publication July 31, 1991; Accepted for publication May 7, 1992

Reprint requests should be addressed to Dr. Toshiki Inokuchi, the Second Department of Internal Medicine, Toho University School of Medicine, 6-11-1 Omori-Nishi, Ota-Ku, Tokyo 143, Japan 
antecubital vein of the opposite hand in each subject at 15-minutes intervals starting from -15 minutes and ending at the 60 minutes mark. EPI infusion was conducted randomly within 3 days of radiologic imaging tests of the liver. The degree of hepatic steatosis was assessed by computed tomography (CT), as previously described (7). The non-obese subjects were confirmed to have non-fatty liver by either $\mathrm{CT}$ or ultrasonography.

Plasma glucose (PG), plasma immunoreactive glucagon (IRG), and serum immunoreactive insulin (IRI) concentrations were measured as previously described (8). Plasma EPI was determined by HPLC after an initial purification on alumina (9). Plasma FFA concentrations were measured by an enzymatic method using a commercial kit (Nihonshoji Co., Japan); plasma glycerol concentrations were measured by an enzymatic method using a commercial kit (UV test, Boehringer Mannheim Yamanouchi Co., Japan). Plasma acetoacetic acid (AcAc) and 3- $\beta$-hydroxybutyric acid (3-OHBA) concentrations were determined by the method of Harano et al (10) using a commercially available kit (Ketone test, Sanwa Kagaku Co., Japan). Here, the term "total ketone body" (TKB) is used to indicate the sum of AcAc and 3-OHBA.

All data are expressed as mean $\pm \mathrm{SD}$, unless otherwise stated. Significance was determined using the two-tailed Student's $t$ test for paired and unpaired data when appropriate. Results were considered significant at $p<0.05$, and levels of significance were similar with both the Wilcoxon's signed-ranks test and Student's $t$ test; the results with Student's t test are presented.

\section{Results}

\section{Clinical features (Table 1)}

On the basis of the liver: spleen ratio in CT numbers, the 12 moderately obese patients were divided into two groups: obese patients without fatty liver $(\mathrm{OBN})(\mathrm{n}=6)$ and those with fatty liver (OBF) $(n=6)$. The ratios were
$1.07 \pm 0.09$ and $0.80 \pm 0.10$ in the OBN and OBF groups, respectively, revealing a significantly $(p<0.01)$ lower value in the OBF than in the OBN group. Mean age and FFM were comparable among the groups, and BMI in the two obese groups was similar. Each of the obese patients clinically showed body fat distribution consistent with his or her sex: the waist-to-hip ratio values were $1.04 \pm 0.03$ and $0.87 \pm 0.03$ in males and females, respectively, showing no significant differences between the two obese groups.

\section{Clinical data at baseline (Table 2)}

The means of the measurement of each variable taken at two time points before beginning EPI infusion were used as basal values. Plasma EPI and PG concentrations were similar among the groups. In contrast, the mean basal IRI, IRG, FFA, and glycerol levels were significantly $(p<0.05-0.01)$ higher in the obese patients than in normals, while there were no significant differences between the two obese groups, except that IRI concentration was significantly $(p<0.01)$ higher in the OBF than in the OBN group. On the other hand, the mean TKB and 3-OHBA concentrations showed significantly $(p<0.05-0.01)$ lower values in the $\mathrm{OBF}$ than in the OBN group, whereas the ratio of TKB to FFA, indicative of a rough estimate of the amount of ketone body production per unit of circulating FFA, was significantly $(p<0.01)$ lower in obese patients than in normals, being lowest in the OBF group.

Relationship of basal FFA and TKB to FFA ratio to the degree of fatty liver in obese patients (Fig. 1)

Basal FFA and TKB/FFA ratio values were significantly correlated with the $\mathrm{CT}$ number ratio $(\mathrm{r}=-0.605 ; \mathrm{p}<0.05$, $\mathrm{n}=12, \mathrm{r}=0.774 ; \mathrm{p}<0.01, \mathrm{n}=12$, respectively), whereas TKB values showed a trend toward correlation with the degree of fatty liver $(r=0.572, p<0.052, n=12)$. In addition, basal FFA was correlated with TKB/FFA ratio value $(r=-0.623 ; p<0.05, n=12)$, whereas it showed no significant correlation with basal TKB levels and BMI. On the

Table 1. Clinical Features of the Subjects

\begin{tabular}{lccccc}
\hline \multicolumn{1}{c}{ Subjects } & $\begin{array}{c}\mathrm{N} \\
(\mathrm{M} / \mathrm{F})\end{array}$ & Age $(\mathrm{yr})$ & BMI $\left(\mathrm{kg} / \mathrm{m}^{2}\right)$ & FFM (kg) & $\begin{array}{c}\text { Liver:spleen ratio } \\
\text { in CT numbers }\end{array}$ \\
\hline Normals & 5 & $27.8 \pm 5.9$ & $20.2 \pm 1.3$ & $51.6 \pm 8.2$ & - \\
& $(3 / 2)$ & $(24-38)$ & $(18.2-21.6)$ & $(42.1-60.3)$ & \\
Obese & 12 & $29.3 \pm 6.9$ & $32.7 \pm 2.2+$ & $59.3 \pm 8.2$ & $0.93 \pm 0.17$ \\
patients (OB) & $(6 / 6)$ & $(17-43)$ & $(30.1-36.8)$ & $(46.7-72.8)$ & $(0.64-1.16)$ \\
$\begin{array}{l}\text { OB without } \\
\text { fatty liver (OBN) }\end{array}$ & 6 & $28.7 \pm 6.7$ & $32.3 \pm 1.3$ & $57.6 \pm 7.5$ & $1.07 \pm 0.09$ \\
OB with & $(3 / 3)$ & $(17-36)$ & $(30.9-34.2)$ & $(47.7-69.1)$ & $(0.97-1.16)$ \\
fatty liver (OBF) & $(3 / 3)$ & $(22-43)$ & $(30.1-36.8)$ & $(46.7-72.8)$ & $(0.64-0.89)$ \\
\hline
\end{tabular}

M: male, F: female, BMI: body mass index, FFM: fat-free mass. Values in parentheses are ranges. ${ }^{H} \mathrm{p}<0.001$ vs normal subjects. ${ }^{* *} \mathrm{p}<0.01, \mathrm{OBN}$ vs $\mathrm{OBF}$. 
Inokuchi et al

Table 2. Baseline Hormonal and Metabolic Characteristics of the Subjects

\begin{tabular}{|c|c|c|c|c|c|c|c|c|c|}
\hline Group & $\begin{array}{c}\text { EPI } \\
(\mathrm{pg} / \mathrm{ml})\end{array}$ & $\begin{array}{c}\text { IRI } \\
(\mu \mathrm{U} / \mathrm{ml})\end{array}$ & $\begin{array}{c}\text { IRG } \\
(\mathrm{pg} / \mathrm{ml})\end{array}$ & $\begin{array}{c}\mathrm{PG} \\
(\mathrm{mg} / \mathrm{d} 1)\end{array}$ & $\begin{array}{c}\text { FFA } \\
(\mathrm{mEq} / \mathrm{l})\end{array}$ & $\begin{array}{c}\text { GLY } \\
(\mathrm{mmol} / \mathrm{l})\end{array}$ & $\begin{array}{c}\text { TKB } \\
(\mu \mathrm{mol} / \mathrm{l})\end{array}$ & $\begin{array}{l}3 \text {-OHBA } \\
(\mu \mathrm{mol} / 1)\end{array}$ & TKB/FFA ratio \\
\hline $\begin{array}{l}\text { Normals } \\
(\mathrm{n}=5)\end{array}$ & $\begin{array}{c}14.0 \pm 6.5 \\
(10-25)\end{array}$ & $\begin{array}{r}6.6 \pm 2.8 \\
(3.2-10.1)\end{array}$ & $\begin{array}{l}71.2 \pm 9.2 \\
(60-82)\end{array}$ & $\begin{array}{l}92.9 \pm 7.3 \\
(83-102)\end{array}$ & $\begin{array}{l}0.36 \pm 0.09 \\
(0.25-0.46)\end{array}$ & $\begin{array}{c}0.06 \pm 0.02 \\
(0.04-0.09)\end{array}$ & $\begin{array}{c}72.6 \pm 19.3 \\
(53.7-95.5)\end{array}$ & $\begin{array}{c}23.7 \pm 13.8 \\
(11.2-40.7)\end{array}$ & $\begin{array}{c}176.2 \pm 60.2 \\
(127.6-260.4)\end{array}$ \\
\hline $\begin{array}{l}\text { Obese } \\
(n=12)\end{array}$ & $\begin{array}{c}13.0 \pm 2.7 \\
(10-17)\end{array}$ & $\begin{array}{c}18.1 \pm 6.7^{+} \\
(9.4-26.3)\end{array}$ & $\begin{array}{c}112.7 \pm 37.8^{+} \\
\quad(82-210)\end{array}$ & $\begin{array}{c}96.8 \pm 9.6 \\
(83-113)\end{array}$ & $\begin{array}{c}0.63 \pm 0.10^{\#} \\
(0.45-0.75)\end{array}$ & $\begin{array}{c}0.16 \pm 0.02^{m} \\
(0.14-0.19)\end{array}$ & $\begin{array}{c}62.0 \pm 18.9 \\
(38.3-104.5)\end{array}$ & $\begin{array}{l}18.6 \pm 13.0 \\
(0.7-49.8)\end{array}$ & $\begin{array}{c}102.1 \pm 36.4 \\
(53.0-153.7)\end{array}$ \\
\hline $\begin{array}{l}\text { OBN } \\
(n=6)\end{array}$ & $\begin{array}{c}13.3 \pm 2.6 \\
(10-15)\end{array}$ & $\begin{array}{c}13.1 \pm 5.8^{+} \\
(9.4-24.7)\end{array}$ & $\begin{array}{c}94.7 \pm 11.9^{\#} \\
(83-115)\end{array}$ & $\begin{array}{c}95.1 \pm 10.0 \\
(83-113)\end{array}$ & $\begin{array}{c}0.58 \pm 0.12^{+} \\
(0.45-0.75)\end{array}$ & $\begin{array}{c}0.16 \pm 0.01 \\
(0.14-0.17)\end{array}$ & $\begin{array}{c}75.6 \pm 14.9 \\
(64.2-104.5)\end{array}$ & $\begin{array}{c}26.5 \pm 12.2 \\
(16.1-49.8)\end{array}$ & $\begin{array}{c}133.2 \pm 19.6 \\
(100.5-153.7)\end{array}$ \\
\hline $\begin{array}{l}\text { OBF } \\
(n=6)\end{array}$ & $\begin{array}{c}12.7 \pm 3.1 \\
(10-17)\end{array}$ & $\begin{array}{r}22.2 \pm 3.9^{* *} \\
(15.2-26.3)\end{array}$ & $\begin{array}{c}134.4 \pm 48.1^{+} \\
\quad(82-210)\end{array}$ & $\begin{array}{l}98.6 \pm 9.8 \\
(83-110)\end{array}$ & $\begin{array}{c}0.68 \pm 0.04^{\#} \\
(0.61-0.73)\end{array}$ & $\begin{array}{c}0.16 \pm 0.02^{\#+} \\
(0.14-0.19)\end{array}$ & $\begin{array}{c}48.4 \pm 11.1^{* *} \\
(38.3-68.0)\end{array}$ & $\begin{array}{l}10.6 \pm 8.6^{*} \\
(0.7-23.1)\end{array}$ & $\begin{array}{c}71.0 \pm 14.6^{* * *} \\
(53.0-94.4)\end{array}$ \\
\hline
\end{tabular}

OBN: obese patients without fatty liver, OBF: obese patients with fatty liver, EPI: epinephrine, PG: plasma glucose, IRI: immunoreactive insulin, IRG: immunoreactive glucagon, FFA: free fatty acid, GLY: glycerol, TKB: total ketone body, 3-OHBA: 3- $\beta$-hydroxybutyric acid. Values in parentheses are ranges. ${ }^{+} \mathrm{p}<0.05,{ }_{\mathrm{p}}<0.01,{ }^{{ }} \mathrm{p}<0.001$ vs normal subjects. ${ }^{*} \mathrm{p}<0.05,{ }^{* *} \mathrm{p}<0.01,{ }^{* * *} \mathrm{p}<0.001$, OBN vs OBF.

BASAL FFA

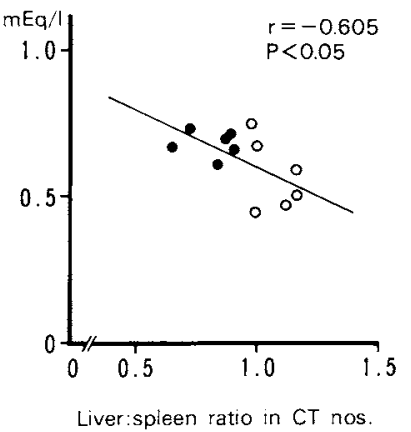

BASAL TK/FFA

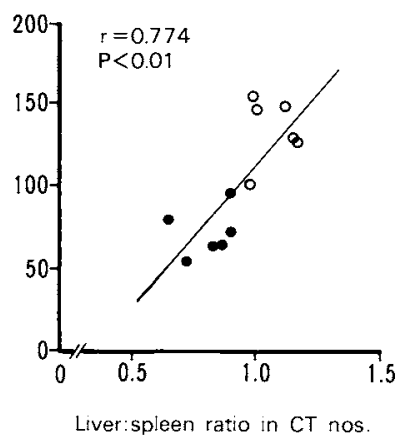

Fig. 1. Relationship of basal FFA and TKB/FFA values to degree of fatty liver in obese patients. O: OBN $(n=6)$, 0 : OBF $(n=6)$. See Table 2 for abbreviations.

other hand, basal IRI concentration also showed a trend toward correlation with the degree of fatty liver $(\mathrm{r}=-0.533 ; \mathrm{p}<0.075, \mathrm{n}=12)$, while basal IRG showed no correlation.

\section{Response to epinephrine infusion (Figs. 2 and 3)}

No adverse effects were experienced by any of the subjects throughout the study. As shown in Fig. 2, the mean EPI concentrations increased, as expected, in a dosedependent fashion, peaking at 60 minutes after beginning the infusion. The obtained values were $312.0 \pm 13.0$, $369.2 \pm 76.2$, and $354.2 \pm 46.7 \mathrm{pg} / \mathrm{ml}$ in the normal, OBN, and $\mathrm{OBF}$ groups ( $\mathrm{p}<0.01$ vs. baseline), respectively, and were comparable at each time point in each group. However, in the OBF group, hyperinsulinemia remained constant, except for 45 -minutes values which were significantly $(\mathrm{p}<0.05)$ suppressed, while the mean IRI levels in the OBN group were comparable to those of the normals only from the 30 - to 60 -minutes time points. On the other

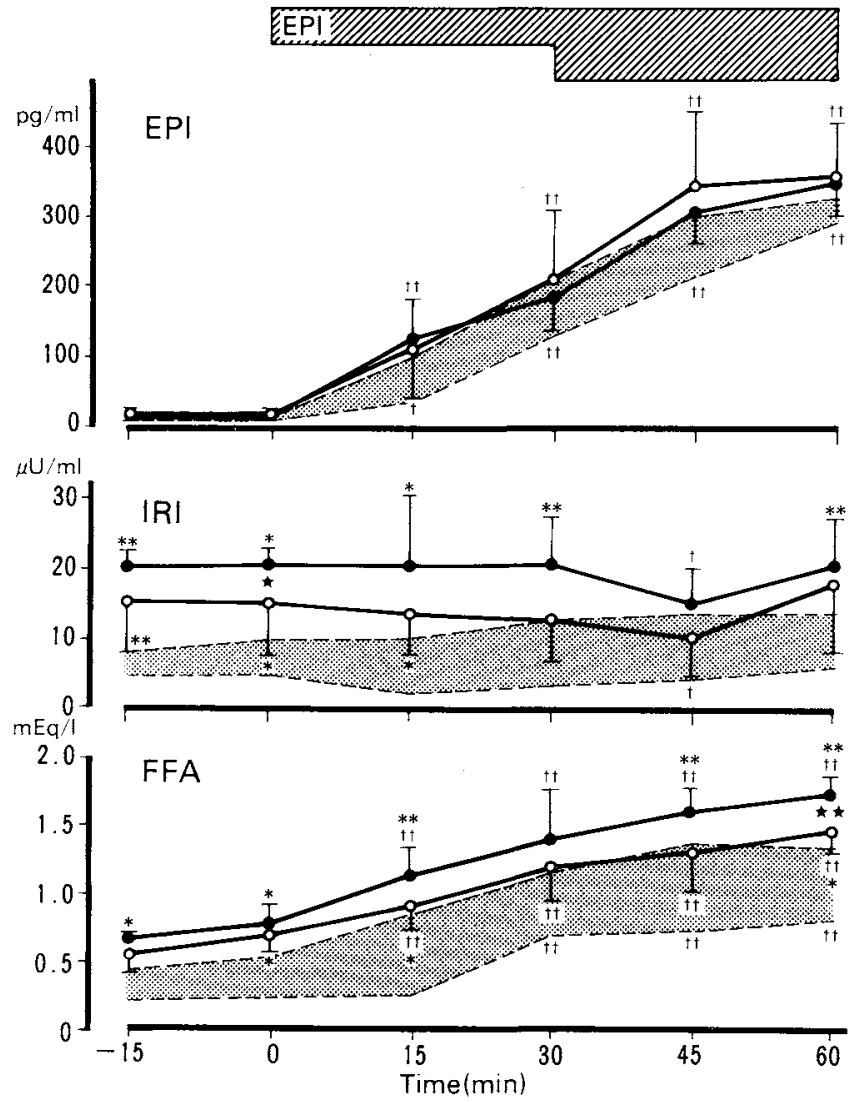

Fig. 2. Changes in plasma EPI, IRI and FFA concentrations during EPI infusion. Shaded area represents the values derived from normal weight subjects $(n=5$, mean $\pm S D), 0-O$ : OBN $(n=6), 0-O B F$ $(n=6) .+p<0.05, \#_{p}<0.01$ vs the corresponding basal values. ${ }^{*} \mathrm{p}<0.05,{ }^{* *} \mathrm{p}<0.01$ vs normal subjects. $\star \mathrm{p}<0.05, \star \star \mathrm{p}<0.01$, OBN vs OBF. See Table 2 for abbreviations.

hand, the mean IRG responses were slightly, but significantly ( $<<0.05$ vs. baseline) greater in the OBF group only from the 30 - to 60 -minutes time points, and showed no 
significant differences from the OBN group $(67.2 \pm 11.0$, $95.0 \pm 4.8$, and $146.5 \pm 67.5 \mathrm{pg} / \mathrm{ml}$ in the normal, $O B N$, and $\mathrm{OBF}$ groups at 60 minutes, respectively), whereas those in the normal and $\mathrm{OBN}$ groups did not change during the infusion. The response of FFA during the infusion progressively increased and peaked at 60 minutes in normals and obese patients; that of glycerol was almost parallel to the FFA pattern throughout the infusion, but was uniformly higher at all time points in the obese patients compared to the normals (Fig. 3). Mean FFA values at the end of EPI infusion were significantly $(p<0.01)$ higher in the OBF than in the OBN group, with significant $(\mathrm{p}<0.05-0.01)$ differences from the normals: $0.97 \pm 0.23,1.36 \pm 0.17$, and $1.64 \pm 0.12 \mathrm{mEq} / \mathrm{L}$ in the normal, OBN, and OBF groups, respectively. With regard to $\mathrm{PG}$, the responses were virtually identical in the normals and obese patients throughout the infusion, peaking at 60 minutes, with no significant differences among the groups $(139 \pm 18,143 \pm 13$, and $153 \pm 27$ $\mathrm{mg} / \mathrm{dl}$ in the normal, OBN, and OBF groups, respectively). TKB and 3-OHBA concentrations progressively increased and peaked at the 60-minutes point in each group. However, both variables in the obese patients. especially in the $\mathrm{OBF}$
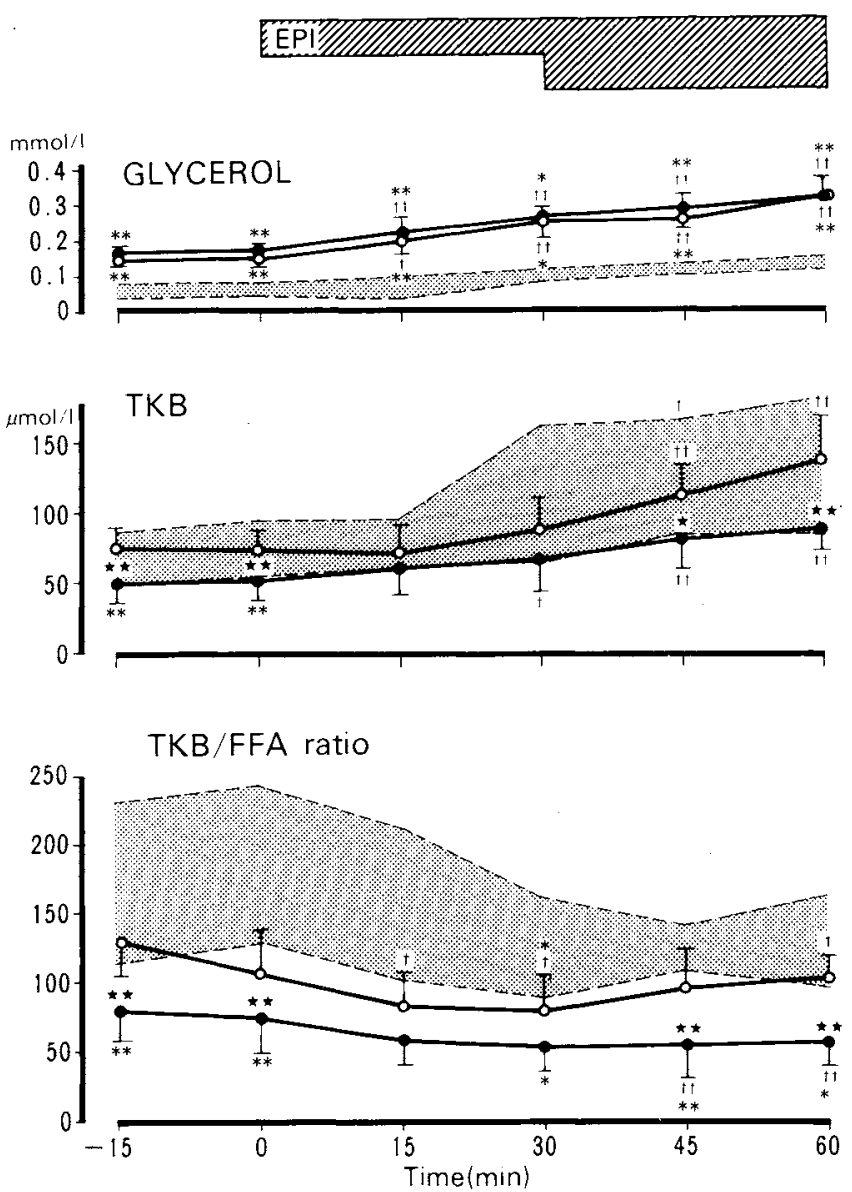

Fig. 3. Changes in plasma glycerol, TKB and TKB/FFA values during EPI infusion. Abbreviations are the same as in Table 2 and Fig. 2. group, showed a blunted rise in response to the infusion, resulting in significantly $(\mathrm{p}<0.01)$ lower levels in the OBF than in the OBN group at the end of the infusion. In contrast, the mean of the TKB:FFA ratio progressively decreased, and reached a nadir at 30- or 45-minutes after beginning the infusion in the normals and the obese patients. The mean ratio in the OBF group was significantly $(p<0.01)$ lower at the 45- to 60-minutes points than in the other two groups.

Comparison of maximal increments from baseline ( $\Delta$ ) of FFA with concomitant changes in the TKB to FFA ratio (Fig. 4)

In response to EPI, the mean FFA increment at the 60 -minutes point was significantly $(p<0.05)$ greater in the obese patients than in the normals, being highest in the OBF group. In contrast, the mean decrement of the TKB/FFA ratio was less pronounced in the obese patients than in the normals, but did not achieve statistical significance because of the large individual variation observed in the normals,

FFA Increment TKB/FFA Decrement
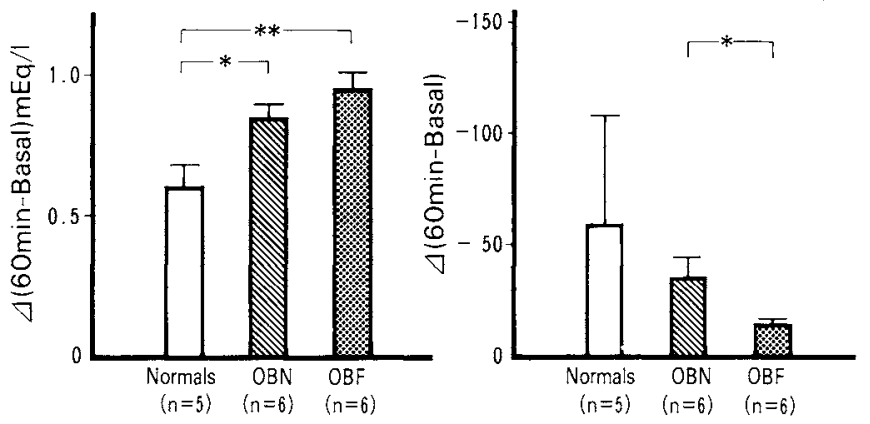

Fig. 4. Comparison of changes ( $\Delta$ ) from basal value in FFA and $\mathrm{TKB} / \mathrm{FFA}$ ratio after 60 minutes infusion. Values are mean $\pm \mathrm{SE}$. Numbers in parentheses. ${ }^{*} p<0.05,{ }^{* *} p<0.01$ vs the corresponding groups. See Table 2 for abbreviations.
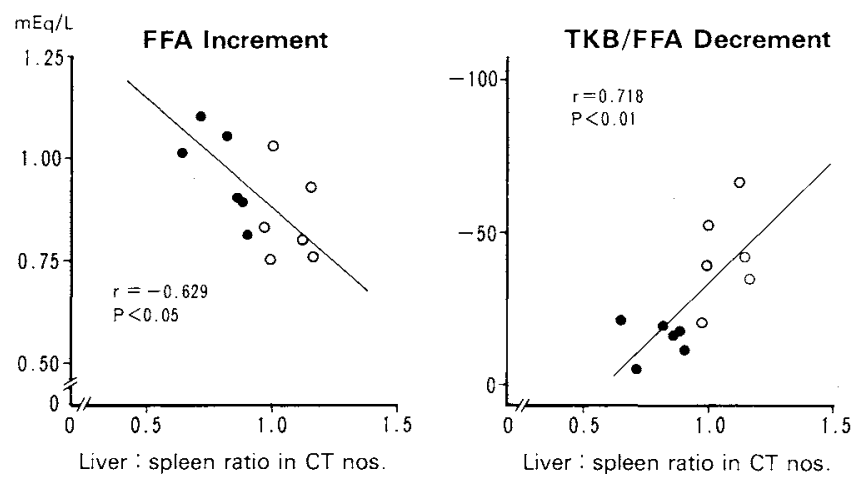

Fig. 5. Relationship between FFA increment, TKB/FFA decrement and degree of fatty liver in obese patients. O: OBN $(n=6): 0: O B F$ $(n=6)$. See Table 2 for abbreviations. 
whereas the decrement was significantly $(p<0.05)$ smaller in the OBF than in the OBN group.

Relation of changes ( $\triangle$ ) in FFA and the TKB to FFA ratio to the degree of fatty liver in obese patients (Fig. 5)

The mean FFA increment and the decrement in the TKB/FFA ratio were found to be significantly correlated with the $C T$ number ratio $(r=-0.629 ; p<0.05, n=12$, $r=0.718 ; p<0.01, n=12$, respectively), whereas the mean decrement in TKB showed no correlation with the degree of fatty liver. In addition, no correlation between changes in FFA and those in other variables, nor between the CT number ratio and other variables could be found.

\section{Discussion}

The present investigation demonstrated that plasma TKB concentrations and the absolute value of the TKB to FFA ratio in basal and EPI-stimulated states decrease markedly in the OBF patients studied, compared with the OBN group, suggesting diminished FFA-induced ketogenesis in obese patients with fatty liver. Our results, furthermore, provide additional evidence that FFA-induced ketogenesis in the subgroup of obese patients is either diminished or indistinguishable from that of normal subjects, indicating that fatty liver per se is closely related to attenuated substrateinduced ketogenesis in some obese patients.

It is well known that lipolysis with a release of plasma FFA substrate is the first step in regulating ketogenesis. Since glycerol is a better indicator of lipolysis than changes in FFA concentration (11), we measured both metabolites as lipolytic indices. In the obese patients, comparable changes were found in concentrations of basal FFA and glycerol, which were significantly greater than in normal subjects. Accordingly, in agreement with previous studies $(3,12)$, the obese patients exhibited accelerated basal lipolysis.

Although the concentration of ketone bodies in the blood represents the balance between their production by the liver and their utilization by peripheral tissues, it has been shown that, within the range of levels observed in our obese patients, increased ketone body utilization by extrahepatic tissues does not contribute to decreased TKB levels $(4,13)$. Consequently, the fact that the TKB/FFA ratio, as well as TKB values in the OBN group, in the presence of excess FFA supply, was indistinguishable from that of the normal subjects suggests that obese patients without fatty liver have an alteration of the intrahepatic fate of FFA, indicating relative resistance to hepatic production of ketone bodies derived from circulating FFA, since plasma FFA are taken up by the liver in a concentration-dependent manner (14, 15). On the other hand, a more markedly reduced $\mathrm{TKB} / \mathrm{FFA}$ ratio as well as TKB values in the OBF group, at comparable FFA levels with the OBN group, could be due to more exaggerated alterations of hepatic FFA metabolism, thus implying the existence of absolute resistance to FFA-induced ketogenesis with subsequent resistance to ketosis.

From a hormonal standpoint, obese patients revealed hyperglucagonemic as well as hyperinsulinemic conditions. In this regard, the OBF group had basal hyperinsulinemia, at comparable FFA and IRG concentrations with the OBN group. More recent reports, also, have demonstrated that glucagon plays little or no role in regulating adipose tissue lipolysis in humans $(12,16)$. Taken together, it seems reasonable to assume that insulin may play a principal role at the level of the adipose tissue as well as the liver (8).

Taking the close correlations found between various variables related to ketone body metabolism and the severity of fatty liver into consideration, it seems possible to presume that, in patients with fatty liver, both hyperinsulinemia and enhanced FFA flux that accompany insulin resistance could result in more increased diversion of FFA toward lipogenesis $(17,18)$, leading to a fatty, triglyceride-laden liver. On the other hand, the lack of direct correlation between circulating FFA and TKB levels would suggest that other alternative factors may contribute in part to reduced hepatic ketone body production, as has been found in animal models (19, 20), although the FFA supply is the primary determinant of ketogenesis.

In the EPI-stimulated state, elevated EPI concentrations, especially in the OBF group, brought about virtually similar findings to the basal state: namely, accelerated lipolysis and diminished FFA-induced ketogenesis. At the plasma levels of EPI induced in this study, previous studies have shown that EPI increases blood flow to the metabolically-active tissues $(21,22)$, and that ketone body production is the major determinant of ketone body concentration $(4,23)$, thus indicating that we did not underestimate the magnitude of lipolysis and the metabolic behavior of ketone bodies. Alternatively, the data suggested that, especially in the OBF group, EPI failed to exert an intrahepatic ketogenic effect, despite the fact that it is a potent ketogenic hormone (5, 14). Moreover, the possibility exists that the transient fall in insulin levels observed during infusion sets the liver into a ketogenic mode, although the reason for this fall in insulin is not known at present. Consequently, it seems likely that EPI concentrations, such as those as observed in moderate stress (5), have, if anything, favored decreased rather than increased diversion of hepatic FFA metabolism toward ketogenesis (15).

Another important aspect of fat mobilization is that EPI is much more lipolytic in the abdominal than in the gluteal/femoral fat depots (24); in our obese patients, the lack of correlation between this greater FFA mobilization observed in the stimulated state and BMI may reflect accelerated lipolysis in specific adipose tissue depots. We could not, however, verify whether or not these associations were independent from total adiposity, especially since we measured peripheral plasma FFA levels alone, not portal FFA.

In summary, these results indicate that a subgroup of 


\section{Resistance to Ketosis in Obesity}

moderately obese patients with normal glucose tolerance has either relative or absolute resistance to substrate-induced ketogenesis, the latter of which may account for the subsequent resistance to ketosis in obese patients, and that fatty liver itself may play an important role in developing the resistance to ketosis. Thus, the presence or absence of fatty liver in obese patients should be considered in evaluating individual obese ketonemia. Obviously, the mechanisms responsible for the findings obtained need confirmation in turnover studies.

Acknowledgements: This work was supported, in part, by the Dr. Takeshi Yanase grant of Toho University School of Medicine.

\section{References}

1) Kekwick A, Pawan GLS, Chalmers TM. Resistance to ketosis in obese subjects. Lancet 2: 1157, 1959.

2) Gordon ES, Goldberg EM, Brandabur JJ, Gee JBL, Rankin J. Abnormal energy metabolism in obesity. Trans Assoc Am Physicians 75: $118,1962$.

3) Balasse E. Influence of norepinephrine, growth hormone and fasting on FFA mobilization and glucose metabolism in lean and obese subjects. Diabetologia 4: 20, 1968.

4) Nosadini R, Avogaro A, Trevisan R, et al. Acetoacetate and 3-hydroxybutyrate kinetics in obese and insulin-dependent diabetic humans. Am J Physiol 248: R611, 1985.

5) Cryer PE. Physiology and pathophysiology of the human sympathoadrenal neuroendocrine system. N Engl J Med 303: 436, 1980.

6) Leonhardt W, Hanefeld M, Julius U, et al. Predictive value of the index of desirable body weight for total body fat mass as measured by dilution of tritiated water - problems and limitations. Int $\mathrm{J}$ Obesity 11: 221, 1987.

7) Inokuchi $\mathrm{T}$, Watanabe $\mathrm{K}$, Kameyama H, Orita M. Altered basal $\mathrm{C}$-peptide/insulin molar ratios in obese patients with fatty liver. Jpn J Med 27: 272, 1988.

8) Inokuchi $T$, Kameyama $H$, Orita $M$, Kasai $T$, Isogai $S$. Elevated pancreatic glucagon in moderately obese patients: relationship of fatty liver and hypertriglyceridemia. Jpn J Med 28: 355, 1989.

9) Ishii M, Kameyama M, Inokuchi T, Isogai S. Plasma fibrinopeptide A levels during insulin-induced plasma glucose falls in diabetes. Diabetes Res Clin Pract 4: 45, 1987.
10) Harano $Y$, Kosugi $T$, Hyosu $S$, Uno S, Ichikawa $Y$, Shigeta $Y$. Sensitive and simplified method for the differential determination of serum levels of ketone bodies. Clin Chem Acta 123: 327, 1983.

11) Wolfe RR, Paters EJ. Lipolytic response to glucose infusion in human subjects. Am J Physiol 252: E218, 1987.

12) Golay A, Swislocki ALM, Chen Y-DI, Jaspan JB, Reaven GM. Effect of obesity on ambient plasma glucose, free fatty acid, insulin, growth hormone, and glucagon concentrations. J Clin Endocrinol Metab 63: 481, 1986.

13) Owen OE, Reichard GA, Markus H, Boden S, Mozzoli MA, Shuman CR. Rapid intravenous sodium acetoacetate infusion in man. Metabolic and kinetic responses. J Clin Invest 52: 2606, 1973.

14) Bahnsen M, Burrin JM, Johnston DG, Pernet A, Walker M, Alberti KGMM. Metabolisms of catecholamine effects on ketogenesis. Am J Physiol 247: E173, 1984.

15) Beylot M, Beaufrere B, Riou JP, et al. Effect of epinephrine on the relationship between nonesterified fatty acid availability and ketone body production in postabsorptive man: evidence for a hepatic antiketogenic effect of epinephrine. J Clin Endocrinol Metab 65: 914, 1987.

16) Jensen MD, Heiling VJ, Miles JM. Effects of glucagon on free fatty acid metabolism in humans. J Clin Endocrinol Metab 72: 308, 1991.

17) Olefsky JM, Farquhar JW, Reaven GM. Reappraisal of the role of insulin in hypertriglyceridemia. Am J Med 57: 551, 1974.

18) Kissebah AH, Alfarsi S, Adams PW, et al. Role of insulin resistance in adipose tissue and liver in the pathogenesis of endogenous hypertriglyceridemia in man. Diabetologia 12: 563, 1976.

19) Triscari J, Greenwood MRC, Sullivan AC. Oxidation and ketogenesis in hepatocytes of lean and obese Zucker rats. Metabolism 31: 223, 1982.

20) Azain MJ, Ontko JA. Ketone body utilization for lipogenesis in the perfused liver of the obese Zucker rat. Horm Metab Res 22: 561, 1990.

21) Weiner N. Norepinephrine, epinephrine and the sympathomimetic amines. in: The Pharmacological Basis of Therapeutics. Gilman AG, Goodman LS, Gilman A, Eds. Macmillan, New York, 1980, p. 138.

22) Hjemdahl $P$, Linde $B$. Influence of circulating $N E$ and Epi on adipose tissue vascular resistance and lipolysis in humans. Am J Physiol 245: H447, 1983.

23) Weiss M, Keller U, Stauffacher W. Effect of epinephrine and somatostatin-induced insulin deficiency on ketone body kinetics and lipolysis in man. Diabetes 33: 738, 1984.

24) Engfeldt P, Arner P. Lipolysis in human adipocytes, effects of cell size, age and of regional differences. Horm Metab Res Suppl 19: $26,1988$. 